\title{
Co-overexpression of TGF- $\beta$ and SOX9 via rAAV gene transfer modulates the metabolic and chondrogenic activities of human bone marrow-derived mesenchymal stem cells
}

Ke Tao 1,2,3, Janina Frisch ${ }^{3}$, Ana Rey-Rico ${ }^{3}$, Jagadeesh K. Venkatesan³ ${ }^{3}$ Gertrud Schmitt ${ }^{3}$, Henning Madry ${ }^{3,4}$, Jianhao Lin ${ }^{1,2}$ and Magali Cucchiarini ${ }^{3^{*}}$

\begin{abstract}
Background: Articular cartilage has a limited potential for self-healing. Transplantation of genetically modified progenitor cells like bone marrow-derived mesenchymal stem cells (MSCs) is an attractive strategy to improve the intrinsic repair capacities of damaged articular cartilage.

Methods: In this study, we examined the potential benefits of co-overexpressing the pleiotropic transformation growth factor beta (TGF- $\beta$ ) with the cartilage-specific transcription factor SOX9 via gene transfer with recombinant adeno-associated virus (rAAV) vectors upon the biological activities of human MSCs (hMSCs). Freshly isolated hMSCs were transduced over time with separate rAAV vectors carrying either TGF- $\beta$ or sox 9 in chondrogenically-induced aggregate cultures to evaluate the efficacy and duration of transgene expression and to monitor the effects of rAAV-mediated genetic modification upon the cellular activities (proliferation, matrix synthesis) and chondrogenic differentiation potency compared with control conditions (lacZ treatment, sequential transductions).

Results: Significant, prolonged TGF- $\beta /$ sox 9 co-overexpression was achieved in chondrogenically-induced hMSCS upon co-transduction via rAAV for up to 21 days, leading to enhanced proliferative, biosynthetic, and chondrogenic activities relative to control treatments, especially when co-applying the candidate vectors at the highest vector doses tested. Optimal co-administration of TGF- $\beta$ with sox 9 also advantageously reduced hypertrophic differentiation of the cells in the conditions applied here.
\end{abstract}

Conclusion: The present findings demonstrate the possibility of modifying MSCs by combined therapeutic gene transfer as potent future strategies for implantation in clinically relevant animal models of cartilage defects in vivo.

Keywords: Human mesenchymal stem cells, Recombinant adeno-associated virus, Multiple gene transfer, Transforming growth factor beta, SOX9, Chondrogenesis

\footnotetext{
* Correspondence: mmcucchiarini@hotmail.com

${ }^{3}$ Center of Experimental Orthopedics, Saarland University Medical Center,

Kirrbergerstraße Bldg 37, Homburg/Saar D-66421, Germany

Full list of author information is available at the end of the article
} 


\section{Background}

Articular cartilage defects are critical problems in orthopedic surgery because this avascular tissue has a restricted ability for self healing in the absence of chondrogenic cells that may contribute to repair processes. Currently available options in the clinics including marrow stimulation techniques (microfracture, pridie drilling, abrasion arthroplasty) to promote the penetration of such cells from the subchondral bone marrow [1, 2], however, do not allow one to reproduce an original cartilage surface in its structure and function, with generation of a fibrocartilaginous repair tissue (type I collagen) of poor mechanical quality instead of the native, highly organized hyaline cartilage (proteoglycans, type II collagen) capable of supporting joint loading and motion [1-4]. While administration of bone marrow-derived mesenchymal stem cells (MSCs), an attractive source of cells for regenerative purposes, has been already attempted in patients to activate the regenerative processes in focal cartilage defects [2, 5-10], the outcomes have not been consistently associated with the formation of functional, hyaline-like repair tissue that fully and stably integrates with the surrounding, intact cartilage.

In this regard, genetic modification of MSCs prior to implantation in sites of cartilage damage might be a potent approach to overcome such issues by enhancing the chondroreparative activities of the cells $[11,12]$. Various gene sequences have been tested thus far as potential chondroregenerative candidates, including the cartilage oligomeric matrix protein (COMP), bone morphogenetic proteins (BMPs), transforming growth factor beta (TGF- $\beta$ ), insulinlike growth factor I (IGF-I), basic fibroblast growth factor (FGF-2), the SOX family of transcription factors, zinc finger protein 145 (ZNF145), Indian hedgehog (Ihh), and Wnt11 [13-24]. Yet reports from diverse groups showed that multiple therapeutic gene transfer might be more valuable to stimulate the repair activities in these cells relative to independent treatments [13, 17, 21, 25-27], a finding also described by us in human articular chondrocytes [28].

In the present study, and for the first time to our best knowledge, we evaluated the possibility of codelivering TGF- $\beta$ and SOX9, two of the most potent chondrogenic factors [29-33], to primary hMSCs as a means to stimulate the chondroreparative activities of such cells as a thorough extension of our previous work using independent application of these agents $[22,23]$. Gene delivery was performed using the attractive, clinically adapted recombinant adeno-associated virus (rAAV) vectors that transduce MSCs at very high efficiencies (up to $100 \%$ ) and over extended periods of time (at least 3 weeks) without altering their differentiation potential $[14,16,22,23]$. Of further note, transduction via rAAV does not raise viral interference, allowing for concomitant administration of independent vectors in their targets [28]. Our data show that successful, prolonged co-overexpression of TGF- $\beta$ and SOX9 via independent gene transfer using this vector class synergically enhances the levels of proliferation, biosynthesis, and chondrogenesis in hMSCs compared with control treatments while delaying undesirable hypertrophic differentiation in vitro. These observations support the concept of modifying MSCs by multiple rAAV vectors as a promising approach for implantation procedures in articular cartilage defects in vivo.

\section{Methods \\ Experimental design}

Human bone marrow-derived mesenchymal stem cells (hMSCs) were pelleted $\left(2 \times 10^{5}\right.$ cells/pellet) and kept in chondrogenic medium $[13,14,16,17,19-24]$ for 24 hours prior to transduction. The hMSC pellets were next treated with the various rAAV vectors or vector combinations according to the following nine conditions for maintenance in chondrogenic medium over a period of 21 days (Fig. 1): group 1, pellets transduced with $40 \mu \mathrm{l}$ rAAV-lacZ; group 2, pellets immediately transduced with $40 \mu \mathrm{l}$ rAAV-lacZ and 1 week later with $40 \mu \mathrm{l}$ rAAV-FLAG-hsox9; group 3, pellets immediately transduced with $40 \mu \mathrm{l}$ rAAV-lacZ and 1 week later with $40 \mu \mathrm{l}$ rAAV-hTGF- $\beta$; group 4, pellets immediately transduced with $40 \mu \mathrm{l}$ rAAV-FLAG-hsox 9 and 1 week later with $40 \mu \mathrm{lAAV}-$ lacZ; group 5, pellets immediately transduced with $40 \mu \mathrm{l}$ rAAV-FLAG-hsox 9 and 1 week later with $40 \mu \mathrm{l}$ rAAV-hTGF- $\beta$; group 6 , pellets immediately transduced with $40 \mu \mathrm{l}$ rAAV-hTGF- $\beta$ and 1 week later with $40 \mu \mathrm{l}$ rAAV-lacZ; group 7 , pellets immediately transduced with $40 \mu \mathrm{l}$ rAAV-hTGF- $\beta$ and 1 week later with $40 \mu \mathrm{l}$ rAAV-FLAG-hsox9; group 8, pellets cotransduced with $20 \mu \mathrm{l}$ rAAV-hTGF- $\beta$ and $20 \mu \mathrm{l}$ rAAV-FLAGhsox9; and group 9, pellets cotransduced with $40 \mu \mathrm{l}$ rAAV-hTGF- $\beta$ and $40 \mu \mathrm{l}$ rAAV-FLAG-hsox 9.

\section{Chemicals and reagents}

All reagents were from Sigma (Munich, Germany) unless otherwise indicated. Recombinant FGF-2 and TGF- $\beta 3$ were purchased at Peprotech (Hamburg, Germany). The dimethylmethylene blue dye was from Serva (Heidelberg, Germany). The anti-TGF- $\beta$ (V) and anti-SOX9 (C-20) antibodies were from Santa Cruz Biotechnology (Heidelberg, Germany), the anti-type II collagen (II-II6B3) antibody from the NIH Hybridoma Bank (University of Iowa, Ames, IA, USA), the anti-type I collagen (AF-5610) antibody from Acris Antibodies (Hiddenhausen, Germany), and the anti-type $\mathrm{X}$ collagen (COL-10) antibody from Sigma. Biotinylated secondary antibodies and the ABC reagent were purchased at Vector Laboratories (Alexis Deutschland $\mathrm{GmbH}$, Grünberg, Germany). The TGF- $\beta$ 


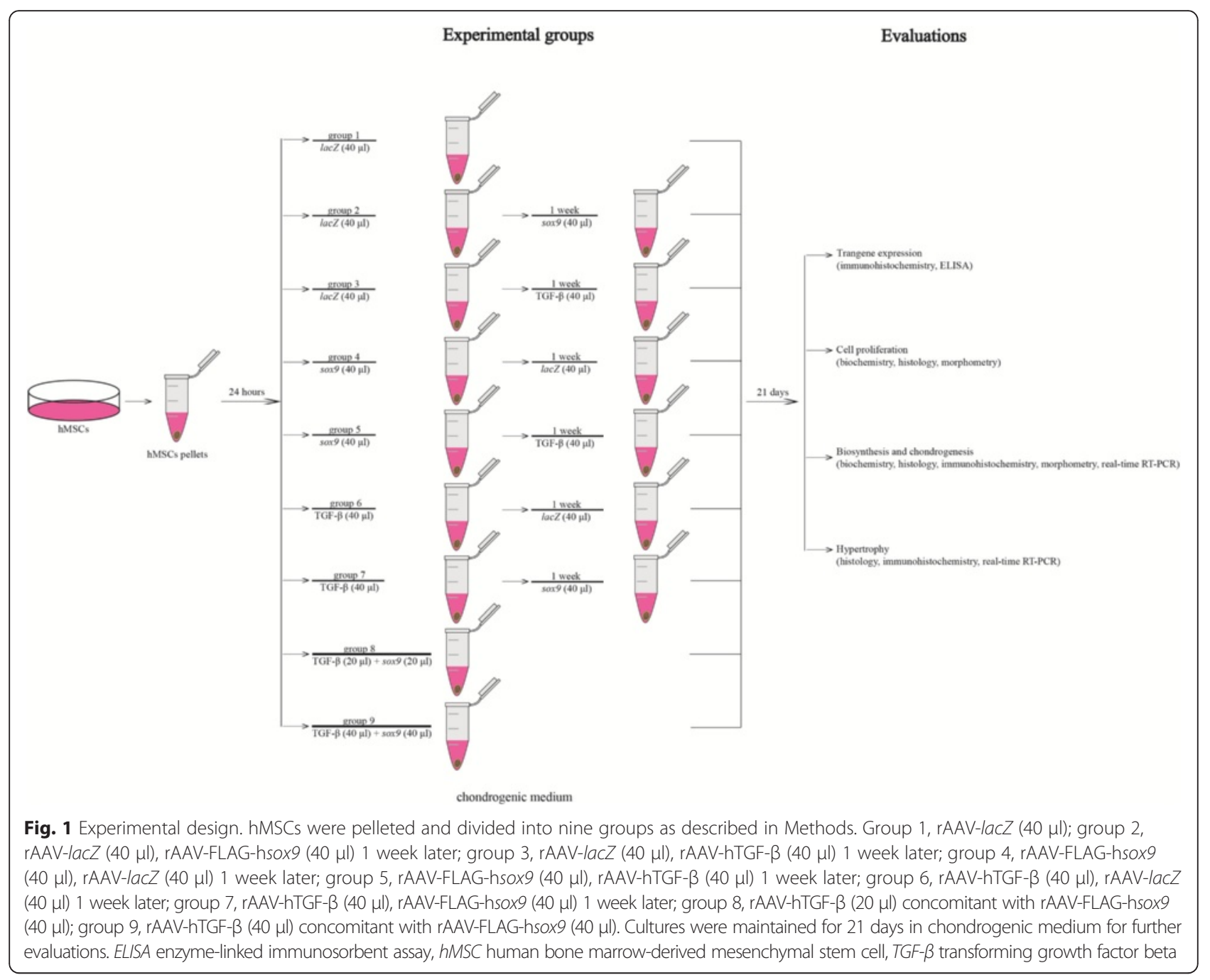

enzyme-linked immunosorbent assay (hTGF- $\beta 1$ Quantikine ELISA) was from R\&D Systems (Wiesbaden, Germany).

\section{Cell culture}

Bone marrow aspirates $(\sim 15 \mathrm{ml})$ were obtained from the distal femurs of osteoarthritic female and male patients undergoing total knee arthroplasty $(n=6)$ (age 69-76 years). The study was approved by the Ethics Committee of the Saarland Physicians Council. All patients provided informed consent before inclusion in the study and all procedures were in accordance with the Helsinki Declaration. hMSCs were isolated and expanded in culture according to standard protocols [16, 22, 23]. Briefly, aspirates were washed in Dulbecco's modified Eagle's medium (DMEM) and centrifuged, and the pellet was resuspended in Red Blood Cell Lysing Buffer in DMEM (1:1). The resulting fraction was washed, pelleted, and resuspended in DMEM containing $10 \%$ fetal bovine serum with $100 \mathrm{U} / \mathrm{ml}$ penicillin and $100 \mu \mathrm{l} / \mathrm{ml}$ streptomycin (growth medium). Cells were plated in T75 flasks and maintained at $37{ }^{\circ} \mathrm{C}$ in a humidified atmosphere with $5 \% \mathrm{CO}_{2}$. The medium was exchanged after 24 hours and every 2-3 days thereafter using growth medium with recombinant FGF-2 (1 ng/ml). Cells were detached and replated for further experiments at the appropriate densities. hMSCs were analyzed by flow cytometry for expression of stem cell surface markers $\left(\mathrm{CD} 71^{+}, \mathrm{CD} 105^{+}\right.$, $\left.\mathrm{CD}^{-} 4^{-}\right)[16,22,23]$. All experiments were performed with cells at no more than passage 2 .

\section{Plasmids and rAAV vectors}

The constructs were all derived from the same parental adeno-associated vector 2 genomic clone, pSSV9 [34, 35]. rAAV-lacZ carries the lacZ gene encoding Escherichia coli $\beta$-galactosidase under the control of the cytomegalovirus immediate-early (CMV-IE) promoter. rAAV-hTGF- $\beta$ carries a $1.2 \mathrm{~kb}$ human active transforming growth factor beta 1 (hTGF- $\beta 1$ ) cDNA fragment (Invivogen, Toulouse, France) and rAAV-FLAG-hsox9 a 1.7 kb FLAG-tagged human sox9 (hsox9) cDNA, both cloned in rAAV-lacZ in 
place of $l a c Z$ [16, 22, 23, 28, 36]. rAAV were packaged as conventional (not self-complementary) vectors in the 293 packaging cell line using Adenovirus 5 and pAd8 for helper functions. Purification, dialysis, and titration of the vectors by real-time PCR were performed as described previously $[16,22,23,28,36]$, averaging $10^{10}$ transgene copies/ml (1/500 functional recombinant viral particles) $[16,22,23,28,36]$.

\section{rAAV-mediated gene transfer}

hMSC aggregate cultures $\left(2 \times 10^{5}\right.$ cells $)$ were prepared and kept for up to 21 days in defined chondrogenic medium (high-glucose DMEM $4.5 \mathrm{~g} / \mathrm{l}$, penicillin/streptomycin, $6.25 \mu \mathrm{g} / \mathrm{ml}$ insulin, $6.25 \mu \mathrm{g} / \mathrm{ml}$ transferrin, $6.25 \mu \mathrm{g} / \mathrm{ml}$ selenous acid, $5.35 \mu \mathrm{g} / \mathrm{ml}$ linoleic acid, $1.25 \mu \mathrm{g} / \mathrm{ml}$ bovine serum albumin, $1 \mathrm{mM}$ sodium pyruvate, $37.5 \mu \mathrm{g} / \mathrm{ml}$ ascorbate 2phosphate, $10^{-7} \mathrm{M}$ dexamethasone, $10 \mathrm{ng} / \mathrm{ml}$ TGF 33 ) for (co)transduction with rAAV (20 or $40 \mu \mathrm{l}$ each vector, $4 \times$ $10^{5}$ or $8 \times 10^{5}$ functional recombinant viral particles, respectively, multiplicity of infection $=2$ or 4 ) $[16,22,23]$.

\section{Transgene expression}

To evaluate the production of TGF- $\beta$, samples were washed twice and placed for 24 hours in serum-free medium. The culture supernatants were collected and centrifuged to remove debris, and TGF- $\beta$ secretion was monitored by ELISA [23]. Quantitative measurements were performed on a GENios spectrophotometer/fluorometer (Tecan, Crailsheim, Germany). Transgene (TGF- $\beta$, SOX9) expression was also assessed by immunohistochemical analyses using specific primary antibodies, biotinylated secondary antibodies, and the $\mathrm{ABC}$ method with diaminobenzidine as the chromogen [16, 22, 23, 28, 36]. To control for secondary immunoglobulins, the samples were processed with omission of the primary antibody. Samples were examined under light microscopy (Olympus BX 45; Olympus, Hamburg, Germany).

\section{Biochemical assays}

hMSC aggregates were collected and digested with papain $[16,22,23,28,36]$. The DNA and proteoglycan contents were determined with a fluorimetric assay using Hoechst 22358 and by binding to dimethylmethylene blue dye, respectively [16, 22, 23]. Data were normalized to total cellular proteins using a protein assay (Pierce Thermo Scientific, Fisher Scientific, Schwerte, Germany). All measurements were performed on a GENios spectrophotometer/fluorometer (Tecan).

\section{Histological and immunohistochemical analyses}

hMSC aggregates were harvested, fixed in $4 \%$ formalin, dehydrated in graded alcohols, embedded in paraffin, and sectioned $(3 \mu \mathrm{m})$. Sections were stained with hematoxylin and eosin ( $\mathrm{H} \& \mathrm{E})$ (cellularity), toluidine blue (matrix proteoglycans), and alizarin red (matrix mineralization) as described previously [16, 22, 23]. Expression of type II/type I/type X collagen was detected by immunohistochemistry using specific primary antibodies as already described [16, 22, 23]. To control for secondary immunoglobulins, sections were processed with omission of the primary antibody. Samples were examined under light microscopy (Olympus BX 45).

\section{Morphometric analyses}

The cell densities on $\mathrm{H}$ \& E-stained sections, the intensities of toluidine blue and alizarin red staining and those of type II and type I collagen immunostaining (pixels per standardized area), and the percentage of cells positive for type $\mathrm{X}$ collagen immunostaining were measured using 10 serial histological and immunohistochemical sections for each parameter, test, and replicate condition using the SIS analySIS program (Olympus), Adobe Photoshop (Adobe Systems, Unterschleissheim, Germany), and Scion Image (Scion Corporation, Frederick, MD, USA) [16, 22, 23].

\section{Real-time RT-PCR analyses}

Total RNA from pellets $(n=3)$ was extracted from the cultures using the RNeasy Protect Mini Kit with an oncolumn RNase-free DNase treatment (Qiagen, Hilden, Germany). RNA was eluted in $30 \mu \mathrm{l}$ RNase-free water. Reverse transcription was carried out with $8 \mu \mathrm{l}$ eluate using the $1^{\text {st }}$ Strand cDNA Synthesis kit for RT-PCR (AMV; Roche Applied Science, Mannheim, Germany). An aliquot of the cDNA product $(2 \mu \mathrm{l})$ was amplified by realtime RT-PCR using the Brilliant SYBR Green QPCR Master Mix (Stratagene, Agilent Technologies, Waldbronn, Germany) on an Mx3000P QPCR operator system (Stratagene) as follows: initial incubation $\left(95{ }^{\circ} \mathrm{C}, 10\right.$ minutes), amplification for 55 cycles (denaturation at $95{ }^{\circ} \mathrm{C}$, 30 seconds; annealing at $55{ }^{\circ} \mathrm{C}, 1$ minute; extension at $72{ }^{\circ} \mathrm{C}, 30$ seconds), denaturation $\left(95^{\circ} \mathrm{C}, 1\right.$ minute), and final incubation $\left(55{ }^{\circ} \mathrm{C}, 30\right.$ seconds). The primers (Invitrogen, Darmstadt, Germany) used were SOX9 (chondrogenic marker) (forward, 5'-ACACACAGCTCACTCGACCTTG-3'; reverse, 5'-GGGAATTCTGG TTGGTCCTCT-3'), aggrecan (ACAN, chondrogenic marker) (forward, 5' -GAGATGGAGGGTGAGGTC-3'; reverse $5^{\prime}$-ACGCTGCCTCGGGCTTC-3'), type II collagen (COL2A1; chondrogenic marker) (forward, $5^{\prime}-\mathrm{G}$ GACTTTTCTCСССТCTCT-3'; reverse, 5'-GACCCG AAGGTCTTACAGGA-3'), type I collagen (COL1A1; osteogenic marker) (forward, 5' -ACGTCCTGGTGAA GTTGGTC-3'; reverse, 5'-ACCAGGGAAGCCTCTC TCTC-3'), type $\mathrm{X}$ collagen (COL10A1; marker of hypertrophy) (forward, 5'-CCCTCTTGTTAGTGCCA ACC-3'; reverse, 5'-AGATTCCAGTCCTTGGGTCA$\left.3^{\prime}\right)$, and glyceraldehyde-3-phosphate dehydrogenase 
(GAPDH; housekeeping gene and internal control) (forward, 5'-GAAGGTGAAGGTCGGAGTC-3'; reverse, 5'-GAAGATGGTGATGGGATTTC-3') (all $150 \mathrm{nM}$ final concentration) $[16,22,23]$. Control conditions included reactions using water and nonreverse-transcribed mRNA. Specificity of the products was confirmed by melting curve analysis and agarose gel electrophoresis. The threshold cycle $(\mathrm{Ct})$ value for each gene of interest was measured for each amplified sample using MxPro QPCR software (Stratagene), and values were normalized to GAPDH expression using the $2^{-\Delta \Delta \mathrm{Ct}}$ method, as described previously $[16,22,23]$.

\section{Statistical analyses}

Each treatment condition was performed in triplicate in three independent experiments for each patient. Data are expressed as the mean \pm standard deviation (SD) of separate experiments. The $t$ test and the Mann-Whitney rank-sum test were used where appropriate. Any $P$ value $<0.05$ was considered statistically significant.

\section{Results}

Effective and sustained TGF- $\beta$ and sox9 co-overexpression in chondrogenically-induced hMSC aggregate cultures via combined rAAV-mediated gene transfer

hMSCs were first transduced with the various $\mathrm{rAAV}$ vectors and vector combinations in chondrogenically-induced aggregate cultures as presented in Fig. 1 to evaluate the ability of this vector class to promote the co-expression of the chondrogenic TGF- $\beta$ and sox 9 genes over time in cells committed toward the chondrocyte phenotype compared with control conditions.

Strong, significant expression of TGF- $\beta$ was noted for at least 21 days especially when the rAAV-hTGF- $\beta$ vector was provided to the cultures, as noted by immunohistochemical analysis that revealed the strongest signal upon concomitant TGF- $\beta$ and $\operatorname{sox} 9$ gene transfer at the highest vector doses applied ( $40 \mu \mathrm{l}$ each vector) (Fig. 2a). This observation was corroborated by results of a specific TGF- $\beta$ ELISA (Fig. $2 b$ ), showing an up to 3 -fold difference when coapplying the TGF- $\beta$ and $\operatorname{sox} 9$ vectors at high vector dose $(40 \mu \mathrm{l}$ each vector $)$ compared with the lac $Z$ condition $(P \leq 0.010)$. Strong SOX9 expression was also achieved for at least 21 days in the cultures in the presence of the rAAV-FLAG-hsox9 vector as noted by immunohistochemistry, also revealing the strongest signal in the simultaneous presence of the TGF- $\beta$ and sox 9 vectors at high vector dose $(40 \mu \mathrm{l}$ each vector) (Fig. 2b).

\section{Effects of co-overexpressing TGF- $\beta$ and sox 9 via rAAV} upon the biological activities and differentiation potential of chondrogenically-induced hMSC aggregate cultures hMSCs were next transduced with the various rAAV vectors and vector combinations in chondrogenicallyinduced aggregate cultures to examine the potential

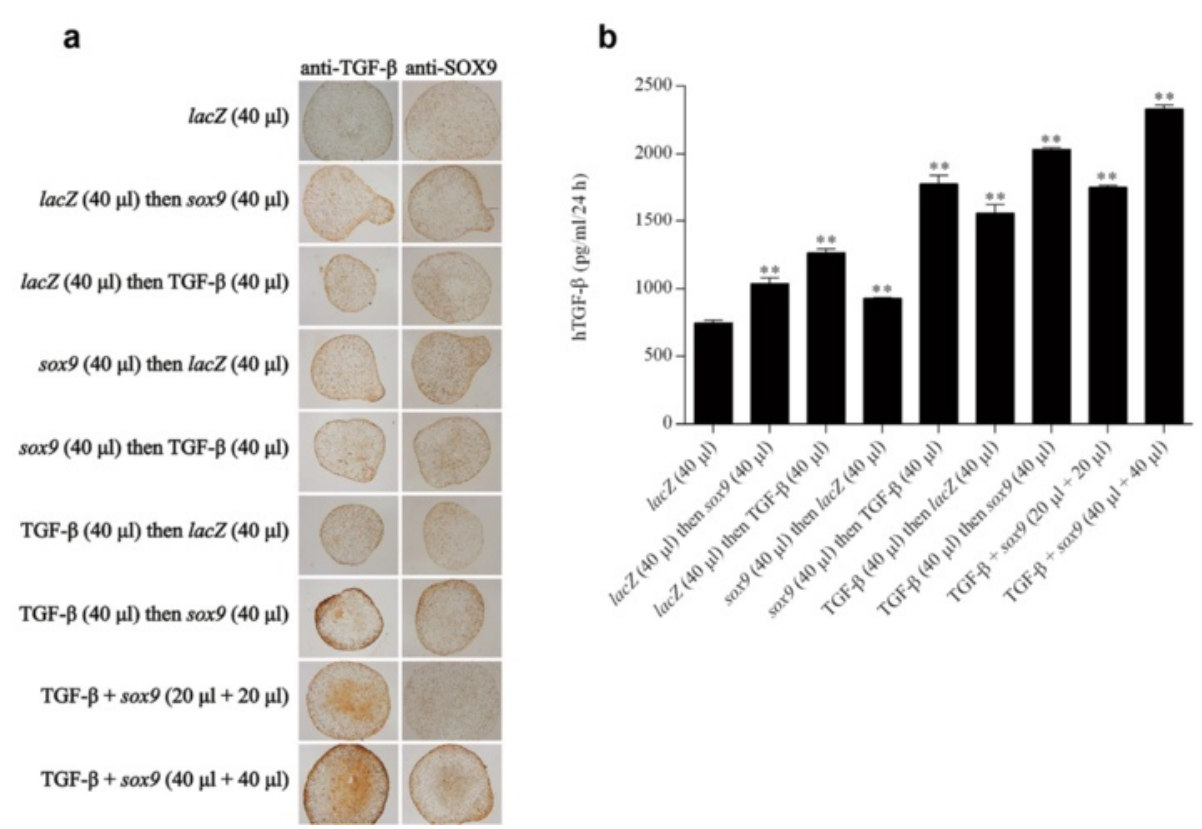

Fig. 2 Transgene expression in chondrogenically-induced hMSCs upon administration of rAAV vectors. hMSC aggregates were transduced with the various vectors or vector combinations as described in Fig. 1 and in Methods. Samples were histologically processed after 21 days to detect the expression of TGF- $\beta$ and SOX9 by immunohistochemistry (magnification $\times 4$; all representative data) $\mathbf{a}$ and to monitor the production of TGF- $\beta$ by ELISA $\mathbf{b}$ as described in Methods. **Statistically significant compared with group 1 (rAAV-lacZ) (**P $\leq 0.010)$. TGF- $\beta$ transforming growth factor beta 
effects of the concomitant TGF- $\beta$ and sox 9 expression over time upon the proliferative, metabolic, and differentiation activities in cells compared with control conditions, with a focus on concomitant TGF- $\beta /$ sox 9 gene transfer at high vector doses based on the findings of optimal transgene co-overexpression.
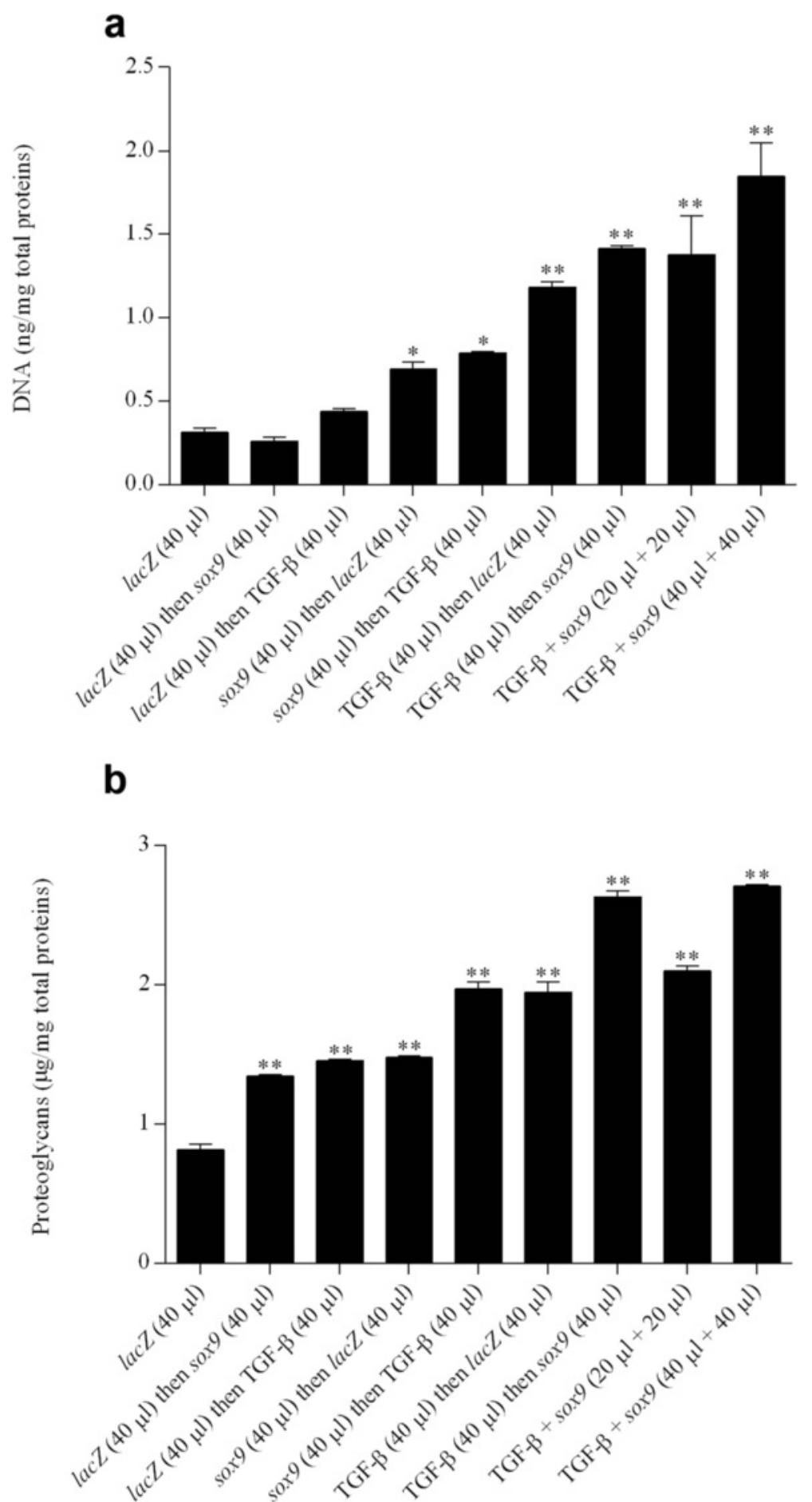

Fig. 3 Biochemical analyses in chondrogenically-induced hMSCs upon administration of rAAV vectors. hMSC aggregates were transduced with the various vectors or vector combinations as described in Fig. 1 and in Methods. Samples were processed after 21 days to monitor the DNA a and proteoglycan contents $\mathbf{b}$ as described in Methods. ${ }^{*}$, Statistically significant compared with group $1($ (rAAV-lac $Z)\left({ }^{*} P \leq 0.050,{ }^{* *} P \leq 0.010\right)$. TGF- $\beta$ transforming growth factor beta 


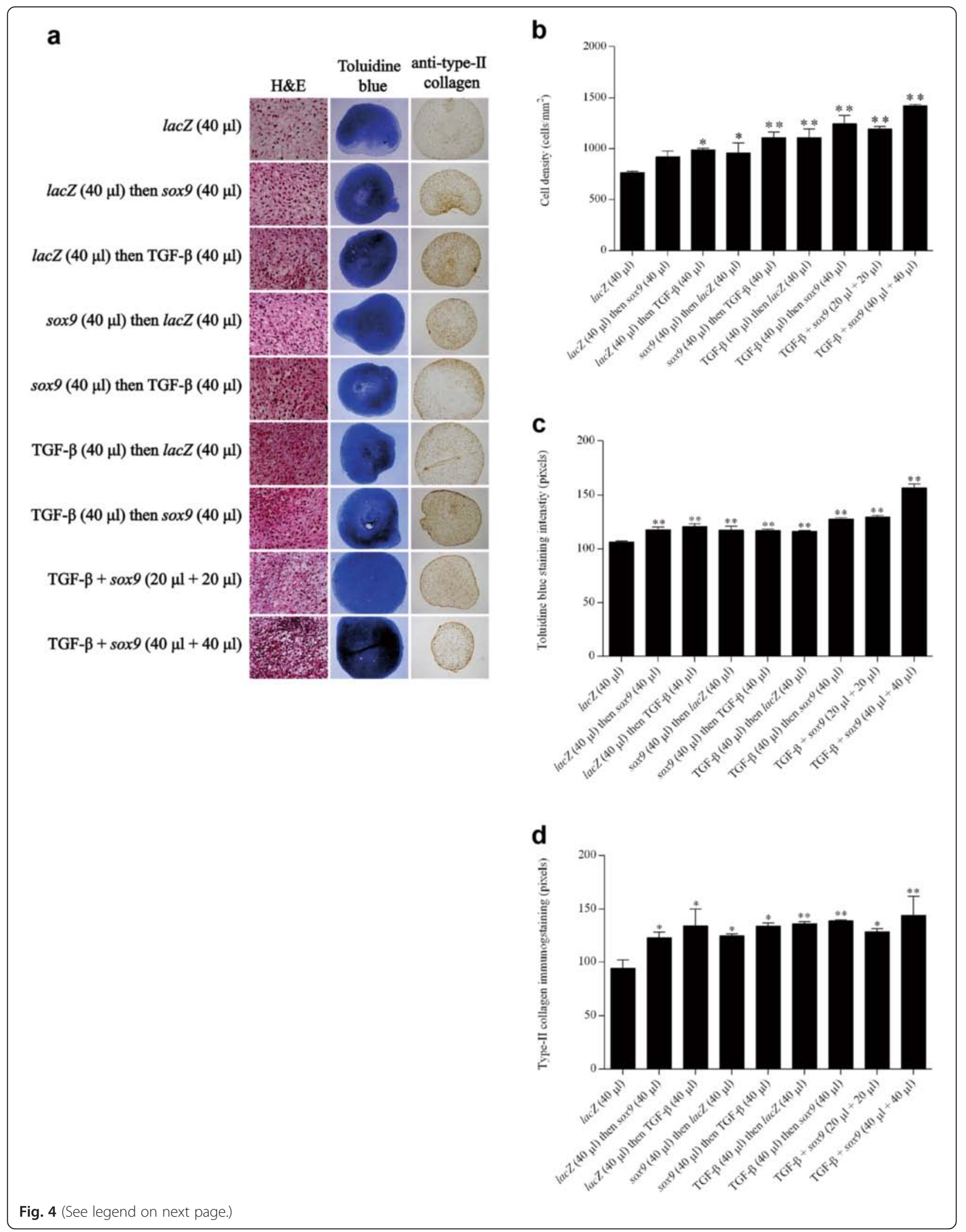


(See figure on previous page.)

Fig. 4 Metabolic and differentiation activities in chondrogenically-induced hMSCs upon administration of rAAV vectors. hMSC aggregates were transduced with the various vectors or vector combinations as described in Fig. 1 and in Methods. Samples were histologically and histomorphometrically processed after 21 days to evaluate cellularity ( $\mathrm{H} \& \mathrm{E}$ staining; magnification $\times 20) \mathbf{a}, \mathbf{b}$ and the deposition of matrix proteoglycans (toluidine blue staining; magnification $\times 4$ ) a, $\mathbf{c}$ and type II collagen (magnification $\times 4$ ) $\mathbf{a}, \mathbf{d}$ as described in Methods (all representative data). ${ }^{* *}$. Statistically significant compared with group 1 (rAAV-lacZ) $\left.{ }^{*} P \leq 0.050 ;{ }^{*} P \leq 0.010\right)$. $H \& E$ hematoxylin and eosin, $T G F-\beta$ transforming growth factor beta

High, significant levels of cell proliferation were noted for at least 21 days especially when rAAV-hTGF- $\beta$ and rAAV-FLAG-hsox 9 were provided at the highest vector doses tested ( $40 \mu \mathrm{l}$ each vector), as noted by an evaluation of the DNA contents in the cultures (7.2-fold difference compared with the lac $Z$ condition; $P \leq 0.010$ ) (Fig. 3a) and of the cell densities on $\mathrm{H} \&$ E-stained histological sections (1.9-fold difference compared with lacZ; $P \leq 0.010$ ) (Fig. 4a, b). Elevated, significant levels of matrix synthesis and chondrogenic differentiation were also reported for at least 21 days especially when the TGF- $\beta$ and sox 9 vectors were administered at the highest vector doses tested ( $40 \mu \mathrm{l}$ each vector), as observed by an estimation of the proteoglycan contents in the cultures (3.4-fold difference compared with lacZ; $P \leq 0.010$ ) (Fig. $3 \mathrm{~b}$ ) and of the intensities of toluidine blue staining (1.4-fold difference compared with lacZ; $P \leq 0.010$ ) (Fig. 4a, c) and of type II collagen immunostaining (1.6-fold difference compared with lacZ; $P \leq 0.010$ ) (Fig. 4a, d). These findings were corroborated by the results of a real-time RT-PCR analysis revealing most particularly enhanced levels of chondrogenic SOX9, ACAN, and COL2A1 expression profiles via concomitant TGF- $\beta$ and sox 9 gene transfer (48-fold, 260 -fold, and 23-fold difference compared with lacZ; $P \leq 0.010$ ) (Fig. 6).

\section{Effects of co-overexpressing TGF- $\beta$ and sox9 via rAAV upon the hypertrophic differentiation processes in chondrogenically-induced hMSC aggregate cultures} Finally, hMSCs were transduced with the various rAAV vectors and vector combinations in chondrogenicallyinduced aggregate cultures to determine the possible impact of the concomitant TGF- $\beta$ and sox 9 expression over time upon hypertrophic events in cells compared with control conditions, again with a focus on the optimal treatment condition.

Remarkably, coadministration of rAAV-hTGF- $\beta$ and rAAV-FLAG-hsox 9 at the highest vector doses tested (40 $\mu \mathrm{l}$ each vector) significantly decreased the levels of hypertrophic differentiation for at least 21 days in the cultures, as noted by an evaluation of the intensities of alizarin red staining (1.2-fold difference compared with lacZ; $P \leq 0.050$ ) (Fig. 5a, b), of type I collagen immunostaining (1.2-fold difference compared with lacZ; $P \leq 0.050$ ) (Fig. 5a, c), and of type X collagen immunostaining (2.9fold difference compared with lacZ; $P \leq 0.010$ ) (Fig. 5a, d).
Once again, these results were corroborated by findings of a real-time RT-PCR analysis revealing most particularly reduced levels of hypertrophic COL1A1 and COL10A1 expression profiles upon TGF- $\beta$ and sox9 co-gene transfer (25-fold and 50-fold difference compared with lacZ; $P \leq 0.010$ ) (Fig. 6).

\section{Discussion}

Strategies based on the administration of genetically modified bone marrow-derived MSCs have attracted increased interest in recent years as a means to enhance the healing processes in articular cartilage defects $[11,12]$. In this study, we tested the possibility of simultaneously targeting hMSCs to overexpress the chondrogenic TGF- $\beta$ and SOX9 factors [29-33] by multiple gene transfer using the potent $\mathrm{rAAV}$ vectors for a possible synergistic, positive impact on the reparative activities of the cells in vitro.

Our results first indicate that concomitant expression of TGF- $\beta$ and sox 9 was successfully achieved via independent rAAV gene transfer in hMSCs in vitro for at least 21 days, probably due to good penetration and maintenance of the vectors in these targets, as previously reported when applying these candidate genes as individual treatments to the cells $[22,23]$. Combined TGF$\beta /$ sox 9 gene transfer allowed for the durable production of TGF- $\beta$ at levels that were higher than those achieved in the control lac $Z$ condition or when providing rAAVhTGF- $\beta$ with rAAV-lacZ instead of rAAV-FLAG-hsox 9 at comparable vector codoses (1.3-fold to 3-fold more elevated concentrations), possibly due to a regulatory, positive effect of exogenous SOX9 factor upon the expression of TGF- $\beta$. More, extensive work on the promoter sequences will be needed to identify possible targets to each factor for trans-expression effects.

The data further show that prolonged, effective cooverexpression of TGF- $\beta$ and sox 9 was capable of enhancing the levels of cell proliferation, matrix biosynthesis, and chondrogenic differentiation in hMSCs over time in vitro (at least 21 days), concordant with the properties of these agents and with our previous work when rAAV-hTGF- $\beta$ and rAAV-FLAG-hsox 9 were independently provided to the cells $[22,23,29-33]$. TGF- $\beta$ / sox9 coapplication was capable of stimulating these activities in hMSCs to levels higher than those reached in the control lac $Z$ condition or when combining each therapeutic sequence with $l a c Z$ at similar vector codoses (1.2-fold to 7.2-fold more potent proliferative, anabolic, 

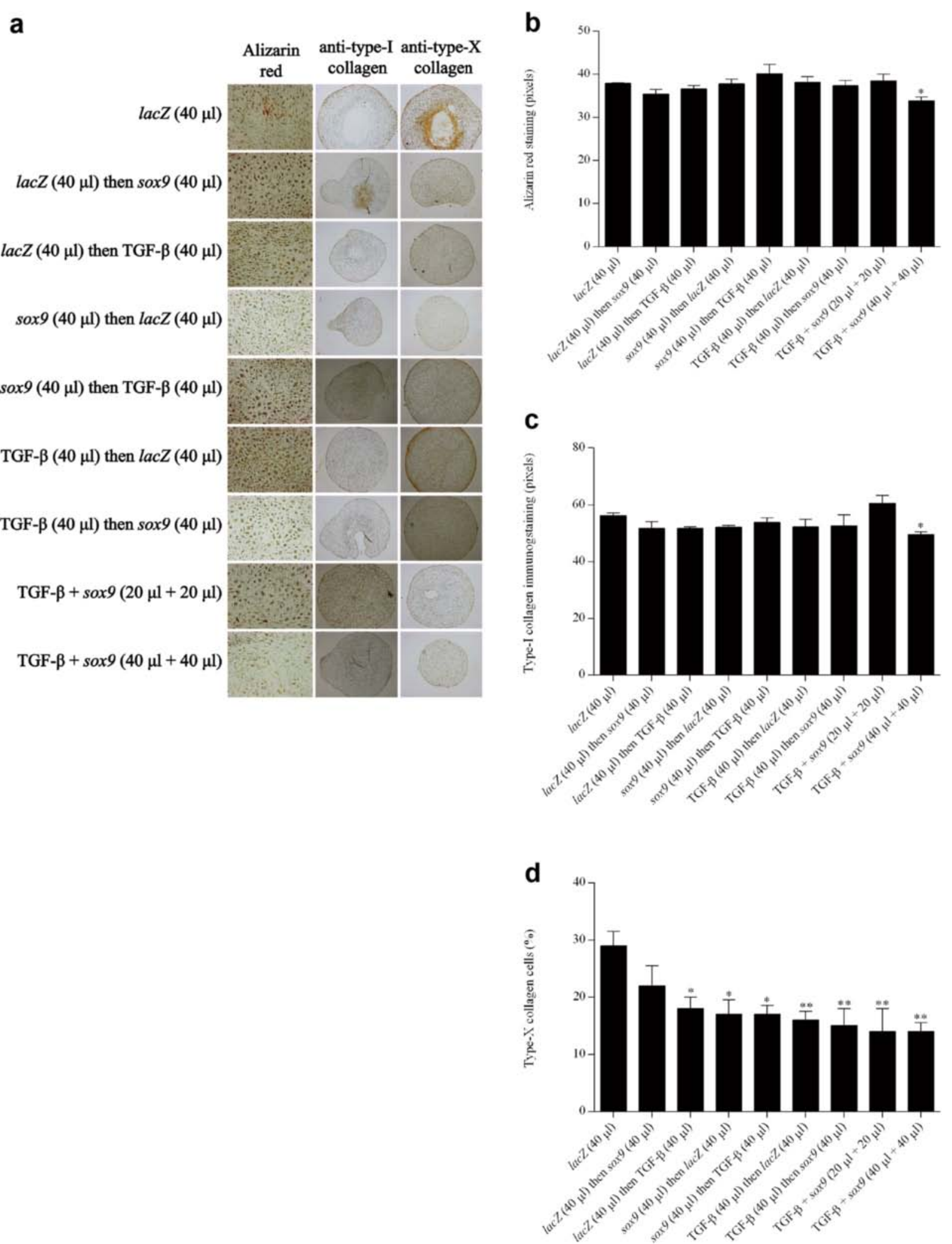

Fig. 5 (See legend on next page.) 
(See figure on previous page.)

Fig. 5 Hypertrophic differentiation in chondrogenically-induced hMSCs upon administration of rAAV vectors. hMSC aggregates were transduced with the various vectors or vector combinations as described in Fig. 1 and in Methods. Samples were histologically and histomorphometrically processed after 21 days to evaluate matrix mineralization (alizarin red staining; magnification $\times 20$ ) $\mathbf{a}, \mathbf{b}$ and the deposition of type I collagen (magnification $\times 4) \mathbf{a}, \mathbf{c}$ and type $X$ collagen (magnification $\times 4) \mathbf{a}, \mathbf{d}$ as described in Methods (all representative data). ${ }^{*}, *$ Statistically significant compared with group 1 (rAAV-lacZ) $\left({ }^{*} P \leq 0.050 ;{ }^{* *} P \leq 0.010\right)$. TGF- $\beta$ transforming growth factor beta

and chondrogenic effects), demonstrating that additive effects could be achieved by simultaneous gene transfer of these two potent factors [37]. Equally important, combined TGF- $\beta / \operatorname{sox} 9$ delivery advantageously delayed premature hypertrophic differentiation in hMSCs relative to lacZ treatment, possibly resulting from antihypertrophic effects of exogenous sox 9 expression [22] that might counterbalance the otherwise prohypertrophic activities of TGF- $\beta[23,30,31,33]$ in the conditions evaluated here. Interestingly, Liao et al. [38] also reported that exogenous overexpression of sox 9 enhanced the chondrogenic differentiation of MSCs comodified by BMP-2, a member of the TGF- $\beta$ superfamily, using coadenoviral vector delivery, while inhibiting their hypertrophic differentiation in vitro.

In conclusion, and for the first time to our best knowledge, we provide evidence for the benefits of cotransducing hMSCs via separate therapeutic rAAV vectors to significantly improve their chondroreparative activities in vitro. Work is ongoing to first corroborate the current findings in similar animal cell populations in vitro that may allow one to evaluate the feasibility of translating these findings in experimental orthotopic animal models of articular cartilage defects that provide a natural environment for chondrogenesis $[14,19,39]$ in order to confirm that sox 9 expression can counteract possible hypertrophic effects of TGF- $\beta$ in vivo $[40,41]$.

\section{Conclusion}

The present findings show the potential of combining stem cell-based and multiple gene-based approaches by administration of independent rAAV gene transfer to interactively stimulate chondroreparative activities of progenitor cells as a means to improve the processes controlling cartilage repair upon future implantation in sites of cartilage injuries.

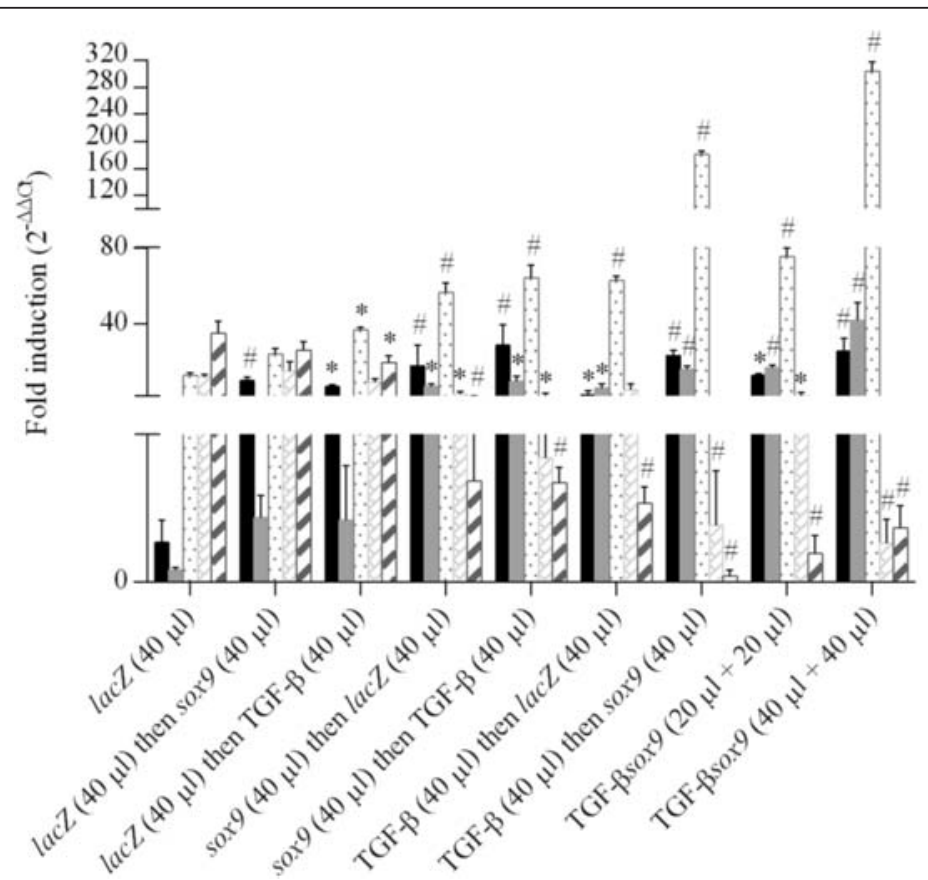

Fig. 6 Expression analyses in chondrogenically-induced hMSCs upon administration of rAAV vectors. hMSC aggregates were transduced with the various vectors or vector combinations as described in Fig. 1 and in Methods. Samples were processed after 21 days to monitor the gene expression profiles by real-time RT-PCR as described in Methods. The genes analyzed included the transcription factor SOX9, aggrecan (ACAN), type II collagen (COL2A1), type I collagen (COL1A1), and type X collagen (COL1OA1), with GAPDH serving as a housekeeping gene and internal control. Threshold cycle $(C t)$ values were obtained for each target and GAPDH as a control for normalization, and fold inductions (relative to lacZ-treated pellets) were measured using the $2^{-\Delta \Delta C t}$ method. ${ }^{*}$, Statistically significant compared with rAAV-lacZ $\left({ }^{*} P \leq 0.050 ;{ }^{*} P \leq 0.010\right)$. TGF- $\beta$ transforming growth factor beta 


\section{Abbreviations}

ACAN: Aggrecan; BMP: Bone morphogenetic protein; CDNA: Complementary deoxyribonucleic acid; CMV-IE: Cytomegalovirus immediate-early; COL10A1: Type X collagen; COL1A1: Type I collagen; COL2A1: Type II collagen; COMP: Cartilage oligomeric matrix protein; Ct: Threshold cycle; DMEM: Dulbecco's modified Eagle's medium; ELISA: Enzyme-linked immunosorbent assay; FGF-2: Basic fibroblast growth factor; GAPDH: Glyceraldehyde-3-phosphate dehydrogenase; $\mathrm{H}$ \& E: Hematoxylin and eosin; hMSC: Human bone marrow-derived mesenchymal stem cell; IGF-I: Insulin-like growth factor I; Ihh: Indian hedgehog; MSC: Mesenchymal stem cell; rAAV: Recombinant adeno-associated virus; RT-PCR: Reverse-transcriptase PCR; SD: Standard deviation; SOX: Sexdetermining region Y-type high mobility group box; TGF- $\beta$ : Transforming growth factor beta; Wnt11: Wingless/Int 11; ZNF145: Zinc finger protein 145

\section{Competing interests}

The authors declare that they have no competing interests.

\section{Authors' contributions}

KT carried out most of the experiments, analyzed and interpreted the data, and was involved in drafting and revising the manuscript. AR-R participated in the experiments and in analyzing the data, and was involved in drafting and revising the manuscript. JF participated in the experiments and in analyzing the data, and was involved in drafting and revising the manuscript. JKV participated in the experiments and in analyzing the data, and was involved in drafting and revising the manuscript. GS participated in the experiments, and was involved in drafting and revising the manuscript. HM made substantial contributions to analysis and interpretation of data and offered critical revision and writing for important intellectual content. JL made substantial contributions to analysis and interpretation of data and offered critical revision and writing for important intellectual content. MC was responsible for conception and design of the experiments and wrote the manuscript. All authors read and approved the final manuscript.

\section{Acknowledgements}

This research was funded by grants from the National Science Foundation of China (NSFC 81441056), the Osteoarthritis Research Society International (OARSI 2015 Scholarship Award), and the German Osteoarthritis Foundation (Deutsche Arthrose-Hilfe e.V.). The authors thank RJ Samulski (Gene Therapy Center, University of North Carolina, Chapel Hill, NC, USA), X Xiao (Gene Therapy Center, University of Pittsburgh, Pittsburgh, PA, USA), and EF Terwilliger (Division of Experimental Medicine, Harvard Institutes of Medicine and Beth Israel Deaconess Medical Center, Boston, MA, USA) for providing the genomic AAV-2 plasmid clones and the 293 cell line, and G Scherer (Institute for Human Genetics and Anthropology, Albert-Ludwig University, Freiburg, Germany) for the human sox9 CDNA

\section{Author details}

${ }^{1}$ Institute of Arthritis, Peking University People's Hospital, Beijing 100044, P.R. China. ${ }^{2}$ Peking University Health Science Center, Beijing 100191, P.R. China. ${ }^{3}$ Center of Experimental Orthopedics, Saarland University Medical Center, Kirrbergerstraße Bldg 37, Homburg/Saar D-66421, Germany. ${ }^{4}$ Department of Orthopaedic Surgery, Saarland University Medical Center, Kirrbergerstr. Bldg 37, Homburg/Saar D-66421, Germany.

Received: 16 October 2015 Revised: 16 December 2015

Accepted: 13 January 2016

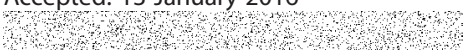

\section{References}

1. Madry H, van Dijk CN, Mueller-Gerbl M. The basic science of the subchondral bone. Knee Surg Sports Traumatol Arthrosc. 2010;18:419-33.

2. Orth P, Rey-Rico A, Venkatesan JK, Madry H, Cucchiarini M. Current perspectives in stem cell research for knee cartilage repair. Stem Cells Cloning. 2014:7:1-17.

3. Breinan HA, Martin SD, Hsu HP, Spector M. Healing of canine articular cartilage defects treated with microfracture, a type-II collagen matrix, or cultured autologous chondrocytes. J Orthop Res. 2000;18:781-9.

4. Frisbie DD, Oxford JT, Southwood L, Trotter GW, Rodkey WG, Steadman JR, et al. Early events in cartilage repair after subchondral bone microfracture. Clin Orthop Relat Res. 2003;407:215-27.
5. Wakitani S, Mitsuoka T, Nakamura N, Toritsuka Y, Nakamura Y, Horibe S. Autologous bone marrow stromal cell transplantation for repair of fullthickness articular cartilage defects in human patellae: two case reports. Cell Transplant. 2004;13:595-600.

6. Kuroda R, Ishida K, Matsumoto T, Akisue T, Fujioka H, Mizuno K, et al. Treatment of a full-thickness articular cartilage defect in the femoral condyle of an athlete with autologous bone-marrow stromal cells. Osteoarthritis Cartilage. 2007;15:226-31.

7. Wakitani S, Nawata M, Tensho K, Okabe T, Machida H, Ohgushi H. Repair of articular cartilage defects in the patello-femoral joint with autologous bone marrow mesenchymal cell transplantation: three case reports involving nine defects in five knees. J Tissue Eng Regen Med. 2007;1:74-9.

8. Haleem AM, Singergy AA, Sabry D, Atta HM, Rashed LA, Chu CR, et al. The clinical use of human culture-expanded autologous bone marrow mesenchymal stem cells transplanted on platelet-rich fibrin glue in the treatment of articular cartilage defects: a pilot study and preliminary results. Cartilage. 2010;1:253-61.

9. Nejadnik H, Hui JH, Feng Choong EP, Tai BC, Lee EH. Autologous bone marrow-derived mesenchymal stem cells versus autologous chondrocyte implantation: an observational cohort study. Am J Sports Med. 2010;38:1110-6.

10. Skowroński J, Rutka M. Osteochondral lesions of the knee reconstructed with mesenchymal stem cells_-results. Ortop Traumatol Rehabil. 2013;15:195-204.

11. Johnstone B, Alini M, Cucchiarini M, Dodge GR, Eglin D, Guilak F, et al. Tissue engineering for articular cartilage repair-the state of the art. Eur Cell Mater. 2013;25:248-67.

12. Frisch J, Venkatesan JK, Rey-Rico A, Madry H, Cucchiarini M. Current progress in stem cell-based gene therapy for articular cartilage repair. Curr Stem Cell Res Ther. 2015;10:121-31.

13. Ikeda T, Kamekura S, Mabuchi A, Kou I, Seki S, Takato T, et al. The combination of SOX5, SOX6, and SOX9 (the SOX trio) provides signals sufficient for induction of permanent cartilage. Arthritis Rheum. 2004;50:3561-73.

14. Pagnotto MR, Wang Z, Karpie JC, Ferretti M, Xiao X, Chu CR. Adeno-associated viral gene transfer of transforming growth factor-beta1 to human mesenchymal stem cells improves cartilage repair. Gene Ther. 2007;14:804-13.

15. Babister JC, Tare RS, Green DW, Inglis S, Mann S, Oreffo RO. Genetic manipulation of human mesenchymal progenitors to promote chondrogenesis using "bead-inbead" polysaccharide capsules. Biomaterials. 2008;29:58-65.

16. Cucchiarini M, Ekici M, Schetting S, Kohn D, Madry H. Metabolic activities and chondrogenic differentiation of human mesenchymal stem cells following recombinant adeno-associated virus-mediated gene transfer and overexpression of fibroblast growth factor 2. Tissue Eng Part A. 2011;17:1921-33.

17. Kim HJ, Im GI. Electroporation-mediated transfer of SOX trio genes (SOX-5, SOX-6, and SOX-9) to enhance the chondrogenesis of mesenchymal stem cells. Stem Cells Dev. 2011;20:2103-14.

18. Lee HH, Haleem AM, Yao V, Li J, Xiao X, Chu CR. Release of bioactive adenoassociated virus from fibrin scaffolds: effects of fibrin glue concentrations. Tissue Eng Part A. 2011;17:1969-78.

19. Liu TM, Guo XM, Tan HS, Hui JH, Lim B, Lee EH. Zinc-finger protein 145 , acting as an upstream regulator of $\mathrm{SOX}$, improves the differentiation potential of human mesenchymal stem cells for cartilage regeneration and repair. Arthritis Rheum. 2011;63:2711-20.

20. Haleem-Smith H, Calderon R, Song Y, Tuan RS, Chen FH. Cartilage oligomeric matrix protein enhances matrix assembly during chondrogenesis of human mesenchymal stem cells. J Cell Biochem. 2012;113:1245-52.

21. Steinert AF, Weissenberger M, Kunz M, Gilbert F, Ghivizzani SC, Göbel S, et al. Indian hedgehog gene transfer is a chondrogenic inducer of human mesenchymal stem cells. Arthritis Res Ther. 2012;14:R168-80.

22. Venkatesan JK, Ekici M, Madry H, Schmitt G, Kohn D, Cucchiarini M. SOX9 gene transfer via safe, stable, replication-defective recombinant adenoassociated virus vectors as a novel, powerful tool to enhance the chondrogenic potential of human mesenchymal stem cells. Stem Cell Res Ther. 2012;3:22-36.

23. Frisch J, Venkatesan JK, Rey-Rico A, Schmitt G, Madry H, Cucchiarini M. Determination of the chondrogenic differentiation processes in human bone marrow-derived mesenchymal stem cells genetically modified to overexpress transforming growth factor- $\beta$ via recombinant adeno-associated viral vectors. Hum Gene Ther. 2014;25:1050-60.

24. Liu S, Zhang E, Yang M, Lu L. Overexpression of Wnt11 promotes chondrogenic differentiation of bone marrow-derived mesenchymal stem cells in synergism with TGF-3. Mol Cell Biochem. 2014;390:123-31.

25. Steinert AF, Palmer GD, Pilapil C, Nöth U, Evans CH, Ghivizzani SC. Enhanced in vitro chondrogenesis of primary mesenchymal stem cells by combined gene transfer. Tissue Eng Part A. 2009;15:1127-39. 
26. Jeon SY, Park JS, Yang HN, Woo DG, Park KH. Co-delivery of SOX9 genes and anti-Cbfa-1 siRNA coated onto PLGA nanoparticles for chondrogenesis of human MSCs. Biomaterials. 2012;33:4413-23.

27. Liu P, Sun L, Chen H, Sun S, Zhou D, Pang B, et al. Lentiviral-mediated multiple gene transfer to chondrocytes promotes chondrocyte differentiation and bone formation in rabbit bone marrow-derived mesenchymal stem cells. Oncol Rep. 2015;34:2618-26

28. Cucchiarini M, Terwilliger EF, Kohn D, Madry H. Remodelling of human osteoarthritic cartilage by FGF-2, alone or combined with Sox9 via rAAV gene transfer. J Cell Mol Med. 2009;13:2476-88.

29. Johnstone B, Hering TM, Caplan Al, Goldberg VM, Yoo JU. In vitro chondrogenesis of bone marrow-derived mesenchymal progenitor cells. Exp Cell Res. 1998;238:265-72.

30. Mackay AM, Beck SC, Murphy JM, Barry FP, Chichester CO, Pittenger MF. Chondrogenic differentiation of cultured human mesenchymal stem cells from marrow. Tissue Eng. 1998;4:415-28.

31. Yoo JU, Barthel TS, Nishimura K, Solchaga L, Caplan Al, Goldberg VM, et al. The chondrogenic potential of human bone-marrow-derived mesenchymal progenitor cells. J Bone Joint Surg Am. 1998;80:1745-57.

32. Bi W, Deng JM, Zhang Z, Behringer RR, de Crombrugghe B. Sox9 is required for cartilage formation. Nat Genet. 1999;22:85-9.

33. Barry F, Boynton RE, Liu B, Murphy JM. Chondrogenic differentiation of mesenchymal stem cells from bone marrow: differentiation-dependent gene expression of matrix components. Exp Cell Res. 2001;268:189-200.

34. Samulski RJ, Chang LS, Shenk T. A recombinant plasmid from which an infectious adeno-associated virus genome can be excised in vitro and its use to study viral replication. J Virol. 1987;61:3096-101.

35. Samulski RJ, Chang LS, Shenk T. Helper-free stocks of recombinant adenoassociated viruses: normal integration does not require viral gene expression. J Virol. 1989;63:3822-8.

36. Cucchiarini M, Thurn T, Weimer A, Kohn D, Terwilliger EF, Madry H. Restoration of the extracellular matrix in human osteoarthritic articular cartilage by overexpression of the transcription factor SOX9. Arthritis Rheum. 2007;56:158-67.

37. Park JS, Yang HN, Woo DG, Jeon SY, Park KH. SOX9 gene plus heparinized TGF- $\beta 3$ coated dexamethasone loaded PLGA microspheres for inducement of chondrogenesis of hMSCs. Biomaterials. 2012;33:7151-63.

38. Liao J, Hu N, Zhou N, Lin L, Zhao C, Yi S, et al. Sox9 potentiates BMP2-induced chondrogenic differentiation and inhibits BMP2-induced osteogenic differentiation. PLoS One. 2014;9:e89025-37.

39. Cucchiarini M, Madry H, Ma C, Thurn T, Zurakowski D, Menger MD, et al. Improved tissue repair in articular cartilage defects in vivo by rAAV-mediated overexpression of human fibroblast growth factor 2. Mol Ther. 2005;12:229-38.

40. Bakker $A C$, van de Loo FA, van Beuningen $H M$, Sime $P$, van Lent $P L$, van der Kraan PM, et al. Overexpression of active TGF-beta-1 in the murine knee joint: evidence for synovial-layer-dependent chondro-osteophyte formation. Osteoarthritis Cartilage. 2001;9:128-36.

41. Mi Z, Ghivizzani SC, Lechman E, Glorioso JC, Evans CH, Robbins PD. Adverse effects of adenovirus-mediated gene transfer of human transforming growth factor beta 1 into rabbit knees. Arthritis Res Ther. 2003;5:R132-9.

\section{Submit your next manuscript to BioMed Central and we will help you at every step:}

- We accept pre-submission inquiries

- Our selector tool helps you to find the most relevant journal

- We provide round the clock customer support

- Convenient online submission

- Thorough peer review

- Inclusion in PubMed and all major indexing services

- Maximum visibility for your research

Submit your manuscript at www.biomedcentral.com/submit

) Biomed Central 